\title{
SIMULATION-BASED LAYOUT PLANNING OF A PRODUCTION PLANT
}

\author{
Mert Altinkilinc \\ Department of Engineering Management \& Systems Engineering \\ Old Dominion University \\ Norfolk, VA 23508, U.S.A.
}

\begin{abstract}
This paper presents a study that uses simulation to improve shop floor performance by means of two layout types and certain operational parameters. In this study, an overview of the plant layout problem is covered for the particular company. The original motivation for redesigning the entire shop floor was the need to realize improvements in material flow and output level. First, the performance of the existing system was evaluated by using ARENA. Second, manufacturing cells were formed and group technology layout was developed by means of Rank Order Clustering (ROC) method and Computerized Relative Allocation of Facilities Technique (CRAFT). Finally, the performance of the new system was evaluated and compared with that of the current system.
\end{abstract}

\section{INTRODUCTION}

In this study, functional and group technology layouts of a manufacturing plant was compared to investigate improvements in material flow and output level. Other objectives of the study can be summarized as follows:

- To determine the inherent constraints and the bottlenecks in manufacturing process

- To increase the percentage of annual production quantity completed on time without extra costs including subcontracting and overtime costs

- To provide a solid base for supervision and faceto-face communication.

The existing manufacturing system, which is a typical job shop, has already been in place and operating for several years. It was considered that conversion to a cellular manufacturing system could help to improve quality, eliminate waste, and reduce total manufacturing costs. First, substantial amount of knowledge were accumulated under the light of previous studies related with the comparison of functional and group technology (GT) layouts (e.g. Flynn and Jacobs (1986), Gupta and Leelaket (1993), Morris and Tersine (1994), and Shafer and Meredith
(1993)). As a result, overall understanding of environmental and operational factors that would affect the superiority of cellular manufacturing systems over functional layout systems was developed.

This study can be considered as a contribution to the studies in literature summarized by Agarwal and Sarkis (1998) in the sense that the properties of manufacturing cells that were constructed in this study are different from those of a typical manufacturing cell indicated in literature (e.g. Gaither, Fraizer, and Wei (1990)). The cells designed and used in this study have the following properties:

- Entire shop floor is formed as cells as opposed to the common approach that considers cells as islands within larger job shops.

- The number of machines in each cell is relatively large compared to a typical cell that has four to six machines on average.

- Inter-cell movements are allowed because no additional machine procurement is wanted by the organization.

- Machines of one type are not dedicated to do a specific processing in a cell. They are used in a flexible manner.

- Batch sizes are kept same between GT and functional layouts.

- The flow of jobs through cells is generally in one direction, but bi-directional flows are also allowed.

The remainder of this paper is organized as follows: next section presents the design process. Section III provides the results of the study, and the last section presents the conclusions.

\section{DESIGN OF THE STUDY}

To achieve the objectives of the study, the requirements of the following five steps were sequentially satisfied:

1. Current manufacturing system was modeled and analyzed to determine the performance of the system 
2. Manufacturing cells was constructed using Rank Order Clustering (ROC), a cell formation technique developed by King (1980).

3. Physical layout of machines (intra-cell) and cells (inter-cell) were developed by means of powerful and well known CRAFT algorithm, which is the basis for many computer-aided layout programs.

4. New manufacturing system was modeled and analyzed to determine the system performance according to predetermined performance measures.

5. Functional and GT layouts were compared.

\subsection{Simulation Modeling \& Analysis of the Current System (Functional Layout)}

The manufacturing plant is a typical job shop and parts are manufactured in batches. Batches are produced according to their operation sequences. After parts pass through all of the operations specified in their routing sheets, batches containing these parts are transported to their exit departments which end production activities. Jobs are dispatched according to the rule specified in Table 1 . In the current system, the job, which has the lowest remaining operation time (LVF), is given the highest priority and processed first. This evaluation is made for each machine if there is more than one job waiting to be processed.

Assumptions of the model are as follows:

- Even though the monthly demand for each job type is known in advance, their release time depends on the number of batches calculated according to Table 1.

- Jobs are given priority according to shortest remaining operation time (Low Value First).

- The size of production batches is equal to the size of the transfer batches.

- Machines need to be set up before each operation, and setup time is not a fraction of operation time. Consecutive operation of similar parts on the same machine requires no setup time.

- There are some alternative machines that can be used interchangeably for certain operations of certain job types.

Performance measures can be summarized as follows:

- Percentage of annual production quantity completed on time without extra costs

- Average time spent in the system

- Total distance traveled

- Average number of batches waiting to be processed in front of bottleneck machines

- Average unnecessary time (waits for processing and transportation) spent in the system.
Table 1: Summary of the Dispatching Rule

\begin{tabular}{|c|c|c|c|c|}
\hline $\begin{array}{c}\text { Limits } \\
\text { Determining No. of } \\
\text { Batches }\end{array}$ & $\begin{array}{c}\text { No. of } \\
\text { batches }\end{array}$ & $\begin{array}{c}\text { Individual } \\
\text { Batches }\end{array}$ & $\begin{array}{c}\text { Batch } \\
\text { Size }\end{array}$ & $\begin{array}{c}\text { Release } \\
\text { Time }\end{array}$ \\
\hline 0<Monthly Demand $\leq \mathbf{1 5 0}$ & 1 & 1. & Demand & $1^{\text {st }}$ day \\
\hline \multirow{2}{*}{$\mathbf{1 0}<$ Monthly Demand $\leq 450$} & 2 & 1. & Demand $/ 2$ & $1^{\text {st }}$ day \\
\hline \multirow{2}{*}{$450<$ Monthly Demand } & \multirow{2}{*}{3} & 2. & Demand $/ 2$ & $15^{\text {th }}$ day \\
\cline { 3 - 5 } & & 1. & Demand $/ 3$ & $1^{\text {st }}$ day \\
\cline { 3 - 5 } & & 2. & Demand $/ 3$ & $10^{\text {th }}$ day \\
\hline
\end{tabular}

Simulation runs were conducted based on the experimental design plan shown in Table 2. Results of the overall evaluation, which considers all pair-wise comparisons of 12 alternatives, are given in Table 3. Alternatives were compared under two different situations in terms of monthly demand:

1. Current situation that considers the current demand level for each job type

2. Future situation that considers $20 \%$ increase in demand for each job type

When the current situation was taken into account, the following conclusions were reached. Because the company's primary performance measure was the "percentage of annual production quantity completed on time without extra costs", Alternative 4 were considered as the best alternative. Furthermore, this alternative showed a superior performance than other alternatives $(1,2,3,4,9$, and 10) did except for "average time spent in system."

Table 2: Experimental Design

\begin{tabular}{|c|c|c|c|}
\hline \multirow{4}{*}{ Experiments } & Demand & $\begin{array}{c}\text { Batch Siz } \\
\text { Limits }\end{array}$ & $\begin{array}{c}\text { Scheduling } \\
\text { Rule }\end{array}$ \\
\cline { 2 - 4 } & $\begin{array}{c}\text { Current (-) } \\
1.2 * \text { Current (+) }\end{array}$ & $\begin{array}{c}100-300(*) \\
150-450(-) \\
300-600(+)\end{array}$ & $\begin{array}{c}\text { LVF(ROT) (-) } \\
\text { LVF(SPT) (+) }\end{array}$ \\
\hline 1 & - & - & - \\
\hline 2 & - & - & + \\
\hline 3 & - & + & - \\
\hline 4 & - & + & + \\
\hline 5 & + & - & + \\
\hline 6 & + & - & - \\
\hline 7 & + & + & + \\
\hline 8 & + & + & - \\
\hline 9 & - & $*$ & + \\
\hline 10 & - & $*$ & + \\
\hline 11 & + & $*$ & + \\
\hline 12 & + & & \\
\hline
\end{tabular}

When the future situation was taken into account, the following conclusions were reached. There were two best alternatives according to the company's primary performance measure: Alternatives 6 and 8. When considering other performance measures related with these alternatives, it was also concluded that there was not a significant difference between two according to "average unnecessary time spent in system". However, Alternative 8 presented a 
superior performance than Alternative 6 according to "average number of batches waiting to be processed in front of bottleneck machines". Therefore, Alternative 8 was selected as the best alternative.

These two different situations are shown by column I and II in Table 3, which gives the best alternatives according to each performance measure.

\subsection{Cell Formation \& Layout Design for GT Layout}

According to Fraizer and Spriggs (1996), a GT layout is most appropriate for batch processing because parts are produced in small to medium batches and there is relative stability in the product mix. The GT cell creates a small, cost-effective assembly line within the production operation, but provides much more flexibility than traditional assembly lines. Because each cell is dedicated to producing a group or family of similar parts, switching between similar parts in the family is quick and easy. Only minimal setup time is required, compared with a changeover on an assembly line or with a traditional batch processing or job shop.

\subsubsection{Cell Formation}

Following steps were pursued during the cell formation process:

1. Form the initial part-machine matrix that belongs to the manufacturing system.

2. Follow the steps of ROC method, through the use of a spreadsheet to determine the final partmachine matrix.

3. Make some adjustments heuristically in order to reduce the number of exceptional elements in part-machine matrix by means of considering alternative machines.

When considering the size of the part-machine matrix (54x53) in this study, ROC method seemed to be a viable alternative compared to other methods that might give better results for a wide range of data set sizes (ranging from $100 \times 25$ to 20,000x200) Kaparthi and Suresh (1994). Moreover, ROC method can be easily grasped and applied to realworld problems.

Table 4 specifies machines and job types that belong to three cells determined by the three-step-process above.

Table 4: Specifications for Manufacturing Cells
\begin{tabular}{|c|c|c|}
\hline Cells & $\begin{array}{c}\text { Number of } \\
\text { Machines }\end{array}$ & $\begin{array}{c}\text { Number of } \\
\text { Job Types }\end{array}$ \\
\hline Cell 1 & 23 & 10 \\
\hline Cell 2 & 18 & 15 \\
\hline Cell 3 & 15 & 27 \\
\hline
\end{tabular}

\subsubsection{Layout Design}

Here, cells were considered as job shop cells because of the following reasons:

- It is very difficult to balance workloads between sequential machines to provide smooth flow within a cell because operation and setup times can vary from job to job.

- Operation sequences are not same for all jobs produced in the same cell. In other words, each job type requires different set of machines along its operation sequence.

- The monthly demand for each job type has a fluctuating pattern.

As explained in this section, layout design phase were conducted in two sequential phases:

- Design of the physical layout of machines (intracell). CRAFT algorithm was used to obtain the final layouts of three cells. Result was a layout for each cell that can not be further improved upon by exchanging machines.

Table 3: Best Alternatives according to Predetermined Performance Measures

\begin{tabular}{|l|c|c|}
\hline \multirow{2}{*}{ Performance Measures } & \multicolumn{2}{|c|}{ Experiments (Functional Layout) } \\
\cline { 2 - 3 } & I & II \\
\cline { 2 - 3 } & $\begin{array}{c}\text { (Current Demand) } \\
\text { Experiments }(1,2,3,4,9,10)\end{array}$ & Experiments $(5,6,7,8,11,12)$ \\
\hline $\begin{array}{l}\text { Percentage of annual production quantity } \\
\text { completed on time without extra costs }\end{array}$ & 4 & 6,8 \\
\hline Average time spent in system (minutes) & 9,10 & 11,12 \\
\hline Total distance traveled (meter/year) & 3,4 & 7 \\
\hline $\begin{array}{l}\text { Average number of batches waiting to be } \\
\text { processed in front of bottleneck machines }\end{array}$ & 3,4 & 7,8 \\
\hline Avg. unnecessary time spent in system (min.) & 2,4 & $6,8,12$ \\
\hline
\end{tabular}


- Design of physical layout of cells (inter-cell) and other departments. For heuristic inter-cell design, the following factors were considered:

- In each cell, alternative machines, which are used by certain job types that are normally processed in other cells, were located in a way that will make them easily accessible by those job types.

- Necessary changes were made according to group technology layout (e.g. relocation of forklift and raw material areas, receiving/shipping areas).

\subsection{Simulation Modeling \& Analysis of the New System (GT Layout)}

In GT layout, jobs are still produced in batches. Batches are produced according to their operation sequences, which are determined based on job types. In the new system, there was no change related with machine specifications. Assumptions for the model of the new system are as follows:

- Cell 1,2, and 3 are dedicated to the production of certain job types. But, inter-cell flows are allowed for certain job types because of insufficient number of machines.

- Even though the new system is based on GT layout, some alternative machines are used interchangeably for certain operations of certain job types to prevent machines from being idle when there are some jobs waiting to be processed.

- The distances are taken as 0 between sequential machines (stations).

Performance measures, input variables that are likely to influence them, and different levels of each input variable, which were considered in the analysis of the current system (functional layout), remained same. And, simulation runs were conducted based on the same experimental design plan shown in Table 2. Results of the overall evaluation, which considers all pair-wise comparisons of 12 alternatives, are given in Table 3.

Again, alternatives were compared under two different situations in terms of monthly demand:

1. Current situation that considers the current demand level for each job type

2. Future situation that considers $20 \%$ increase in demand for each job type

These two different situations are shown by column I and II in Table 5, which gives the best alternatives according to each performance measure.

When the current situation was taken into account, the following conclusions were reached. Because the company's primary performance measure was the "percentage of annual production quantity completed on time without extra costs", there were two alternatives that could be considered as the best: Alternatives 2 and 4 . When other performance measures were considered related with those alternatives, it was concluded that even though there was not a significant difference between these two alternatives according to "average unnecessary time spent in system", Alternative 4 presented a superior performance over second alternative according to "average number of batches waiting to be processed in front of bottleneck machines" and "total distance traveled." Therefore, Alternative 4 was selected as the best alternative.

When the future situation was taken into account, the following conclusions were reached. There were three alternatives that could be selected based on the company's primary performance measure: Alternatives 6,7 , and $8 . A l$ ternative 8 presented a superior performance than Alternatives 6 and 7 according to "average number of batches waiting to be processed in front of bottleneck machines", and "total distance traveled"; therefore, it was selected as the best alternative.

Table 5: Best Alternatives according to Predetermined Performance Measures

\begin{tabular}{|l|c|c|}
\hline \multirow{2}{*}{ Performance Measures } & \multicolumn{2}{|c|}{ Experiments (GT Layout) } \\
\cline { 2 - 3 } & I II \\
\cline { 2 - 3 } & Eurrent Demand & $20 \%$ increase in Current Demand \\
Experiments $(1,2,3,4,9,10)$ & Experiments $(5,6,7,8,11,12)$ \\
\hline $\begin{array}{l}\text { Percentage of annual production quantity } \\
\text { completed on time without extra costs }\end{array}$ & 2,4 & $6,7,8$ \\
\hline Average time spent in system (minutes) & 9,10 & 11,12 \\
\hline Total distance traveled (meter/year) & 3,4 & 8 \\
\hline $\begin{array}{l}\text { Average number of batches waiting to be } \\
\text { processed in front of bottleneck machines }\end{array}$ & 3,4 & 8 \\
\hline $\begin{array}{l}\text { Average unnecessary time spent in system } \\
\text { (minutes) }\end{array}$ & 2,4 & $6,8,12$ \\
\hline
\end{tabular}




\section{ANALYSIS OF RESULTS}

The purpose of this section is to present the comparisons made between current and new systems to see the effects of change in layout type.

The comparisons were made between the best alternative of functional layout (Alternative 4) and the best alternative of GT layout (Alternative 4), which is a meaningful representation to summarize the findings of the study. According to this comparison, it was concluded that Alternative 4 of GT layout has higher performance values than those of Alternative 4 of functional layout. Specifications of two alternatives for functional and GT layouts are summarized in Table 6. If Alternative 4, which adopts GT layout, is applied to the current system, the improvements listed in Table 7 can be realized.

\section{CONCLUSIONS}

As a result of the evaluations made between functional and GT layouts, it was concluded that the Alternative 4 of GT layout (new system) has higher performance values than those of Alternative 1 of functional layout (current system). If the results are examined, it is understood that the improvement in primary performance measure is not so significant compared to improvement in other performance measures. The possible reasons behind this result can be explained as follows:

- The negative effect of bottleneck machines on production quantity is more than what the management thinks. In order to prove that, an additional simulation experiment was conducted. The model of Alternative 4, which gives the best results in functional layout, was run by increasing the number (capacity) of each bottleneck machine by one. This alternative was compared with Alternative 1, which represents the current system. As a result, the percentage of annual production quantity completed on time without extra costs increased by 7.4 percent, which is even greater than 4.7 percent given by the best GT layout alternative.

- Some of the machines (e.g. lathes) are so old that the breakdown frequencies of those machines are higher than the expected. Therefore, this reduces the system performance in terms of annual production quantity.

During the study, several alternatives for each layout type were compared and the results were presented. Based on the analysis provided above, the following recommendations were made to the management:

- Stay with an improved functional layout, which is subject to another study. As a result of shorter and more direct routes, production planning and control activities become simpler. Furthermore, production and material handling costs could be reduced, and shop floor space could be used more efficiently.

- Increase the capacity of bottleneck machines.

- Apply GT layout for a particular family of parts as a pilot application to see quantitative and qualitative advantages of cellular manufacturing systems. Many decisions in cell system design are technical in nature; however, there are considerable human aspects to cell design. Many of the failures and problems in CM implementations occur at the interface of the technical and social subsystems. Therefore, the cells should be designed by considering the socio-technical system principles to cell design examined by Hyer, Brown, and Zimmerman (1999).

Table 6: Specifications for Alternatives

\begin{tabular}{|c|c|c|c|c|}
\hline Alternatives & Layout Type & Demand Size & Limits Determining the Batch Size & Scheduling Rule \\
\hline 4 & Functional & Current & $300-600$ & Shortest Processing Time \\
\hline 4 & GT & Current & $300-600$ & Shortest Processing Time \\
\hline
\end{tabular}

Table 7: Improvements

\begin{tabular}{|c|c|c|c|}
\hline \multirow{3}{*}{\multicolumn{2}{|c|}{ Performance Measures }} & \multicolumn{2}{|c|}{ Improvements \& Changes (\%) } \\
\hline & & \multirow[b]{2}{*}{ Current Demand } & \multirow{2}{*}{$\begin{array}{c}\text { II } \\
20 \% \text { increase in } \\
\text { Current Demand }\end{array}$} \\
\hline & & & \\
\hline \multicolumn{2}{|c|}{ Percentage of annual production quantity completed on time without extra costs } & $\uparrow 1.9 \%$ & $\uparrow 3.5 \%$ \\
\hline \multicolumn{2}{|c|}{ Average time spent in system } & $\downarrow 1.68 \%$ & $\downarrow 5.8 \%$ \\
\hline \multicolumn{2}{|l|}{ Total distance traveled } & $\downarrow 52.6 \%$ & $\downarrow 53.4 \%$ \\
\hline \multirow{2}{*}{$\begin{array}{l}\text { Average number of batches waiting to be processed in front of } \\
\text { bottleneck machines }\end{array}$} & Machine 1 & $\downarrow 8.5 \%$ & $\downarrow 9.5 \%$ \\
\hline & Machine 2 & same level & $\downarrow 2.30 \%$ \\
\hline \multirow{2}{*}{ Average unnecessary time spent in system } & Job type 14 & $\downarrow 3.85 \%$ & $\downarrow 3.64 \%$ \\
\hline & Job type 22 & $\downarrow 6.2 \%$ & $\downarrow 8.1 \%$ \\
\hline
\end{tabular}


- Do a long-term cost-benefit analysis for further progress if the experience gained from this pilot application is positive and can be expanded to the whole plant.

\section{REFERENCES}

Agarwal, A., and J. Sarkis. 1998. A Review and Analysis of Comparative Performance Studies on Functional and Cellular Manufacturing Layouts. Computers \& Industrial Engineering. 34: 77-89.

Flynn, B.B., and F.R. Jacobs. 1986. A Simulation Comparison of Group Technology with Traditional Job Shop Manufacturing. International Journal of Production Research. 24: 1171-1192.

Fraizer, G.V., and M.T. Spriggs. May-June 1996. Achieving Competitive Advantage through Group Technology. Business Horizons. 39 (3): 83-90.

Gaither, N., G.V. Fraizer, and J.C. Wei. 1990. From Job Shops to Manufacturing Cells. Production and Inventory Management Journal. 4: 33-36.

Gupta, T. and S. Leelaket. 1993. A Simulation Study Comparing GT vs. Job Shop Manufacturing Systems. Computers \& Industrial Engineering. 25 (1-4): 195198.

Hyer, N.L., K.A. Brown, and S. Zimmerman. 1999. A socio-technical systems approach to cell design: case study and analysis. Journal of Operations Management. 17: 179-203.

Kaparthi, S., and N.C. Suresh. 1994. Performance of Selected Part-Machine Grouping Techniques for Data Sets of Wide Ranging Sizes and Imperfection. Decision Sciences. 25(4): 515-539.

King, J.R. 1980. Machine-Component Grouping in Production Flow Analysis: an approach using rank order clustering algorithm. International Journal of Production Research. 18 (2): 213-232.

Morris, J.S. and R.J. Tersine. 1994. A Simulation Comparison of Process and Cellular Layouts in a Dual Resource Constrained Environment. Computers \& Industrial Engineering. 26: 733-741.

Shafer, M.S. and J.R. Meredith. 1993. An Empiricallybased Simulation Study of Functional versus Cellular Layouts with Operations Overlapping. International Journal of Operations \& Production Management. 13: 47-63.

\section{AUTHOR BIOGRAPHY}

MERT ALTINKILINC is a Ph.D. student in the Department of Engineering Management and Systems Engineering at Old Dominion University (ODU). He has a B.S. (1997) and a M.S. (2000) in Industrial Engineering from Dokuz Eylul University in Turkey and an M.B.A. (2002) concentrated on Information Technology Management from Old Dominion University. His research interests include quality management systems, project integration management, organizational assessment, simulation modeling $\&$ analysis of manufacturing and service systems. His e-mail address is $<$ malti001@odu . edu $>$. 